\title{
Rituximab-Induced Hypogammaglobulinemia and Infections in AQP4 and MOG Antibody-Associated Diseases
}

\author{
Alexandre Avouac, MD, Adil Maarouf, MD, PhD, Jan-Patrick Stellmann, MD, PhD, Audrey Rico, MD, PhD, \\ Clemence Boutiere, MD, Sarah Demortiere, MD, Romain Marignier, MD, PhD, Jean Pelletier, MD, PhD, and \\ Bertrand Audoin, MD, PhD
}

Neurol Neuroimmunol Neuroinflamm 2021;8:e977. doi:10.1212/NXI.0000000000000977

\section{Abstract}

\section{Objective}

To determine the potential association between infections and rituximab (RTX)-induced hypogammaglobulinemia among patients with CNS inflammatory diseases.

\section{Methods}

We included in a prospective observational study all consecutive adults with aquaporin 4 (AQP4) or myelin oligodendrocyte glycoprotein (MOG) antibody-positive disorders treated with RTX. Dosing schedule was adapted to memory B-cell measurement.

\section{Results}

We included 48 patients (mean age 47 [SD: 14] years; 77\% females; 31 AQP4 positive and 17 MOG positive). The median follow-up was 3.6 years (range: $0.9-8.1$ years). The median number of RTX infusions was 8 (range: 2-14). The median dosing interval was 6 months (range: 1.7-13.7 months). Sixty-seven symptomatic infections (SIs) were observed in 26 of 48 (54\%) patients, including 13 severe infections in 9 (19\%). Urinary and lower respiratory tract infections were the most frequent, representing $42 \%$ and $21 \%$ of SI. At RTX onset, the immunoglobulin G (IgG) level was abnormal in 3 of 48 (6\%) patients. After RTX, 15 (31\%), 11 (23\%), 3 (6\%), and 0 of 48 patients showed sustained IgG level $<7,<6,<4$, and $<2 \mathrm{~g} / \mathrm{L}$, respectively. On multivariate Cox proportional hazards analysis, the main variables explaining the risk of SI were the presence of urinary tract dysfunction (hazard ratio [HR] $=34,95 \% \mathrm{CI}$ $4-262, p<0.001$ ), the dosing intervals (HR $=0.98,95 \%$ CI $0.97-0.99, p<0.001$ ), and the interaction between IgG level and urinary tract dysfunction $(\mathrm{HR}=0.67,95 \% \mathrm{CI} 0.53-0.85, p<$ 0.005). IgG level $<6 \mathrm{~g} / \mathrm{L}$ during RTX was associated with male sex $(\mathrm{HR}=4,95 \% \mathrm{CI} 1.4-11.4, p$ $<0.01)$ and previous immunosuppression $(\mathrm{HR}=3.4,95 \%$ CI $1.2-10, p<0.05)$.

\section{Conclusions}

RTX used as maintenance therapy in CNS inflammatory diseases is frequently associated with reduced IgG level and increases the infection risk of the most vulnerable patients.

\author{
Correspondence \\ Dr. Audoin \\ bertrand.audoin@ap-hm.fr
}




\section{Glossary}

AQP4 = aquaporin 4; HR = hazard ratio; IgG = immunoglobulin G; MOG = myelin oligodendrocyte glycoprotein; NMOSD = neuromyelitis optica spectrum disorder; $\mathbf{R T X}=$ rituximab.

B cell-depleting therapy with anti-CD20 drugs is now widely used in CNS inflammatory diseases including MS and aquaporin 4 (AQP4)-antibody-positive neuromyelitis optica spectrum disorders (NMOSDs). In CNS inflammatory diseases, B celldepleting therapy is typically used as maintenance therapy, which contrasts with its use in many non-neurologic diseases, in which the therapy is usually used as a short-term remissioninducing agent.

Recently, a nationwide register-based cohort raised safety concerns related to the use of anti-CD20 agents as maintenance therapy in MS, demonstrating the highest risk of infection with rituximab (RTX) used every 6-12 months compared with other highly effective disease-modifying therapies. ${ }^{1}$ Thus, the long-term safety of anti-CD20 agents used as maintenance therapy for CNS inflammatory diseases remains to be fully established. Particularly, mechanisms underlying infections associated with maintenance therapy with anti-CD20 agents must be identified. For non-neurologic diseases, including adult lymphoma and rheumatic diseases, hypogammaglobulinemia and especially reduced serum level of immunoglobulin G ( $\operatorname{IgG}$ ) have been found as an independent predictor of infections in patients receiving $\mathrm{RTX}^{2-6}$ Thus, guidelines have emerged for managing secondary hypogammaglobulinemia due to anti-CD20 therapy in autoimmune rheumatic diseases. ${ }^{7}$

Here, we report the safety data of a recent published prospective observational study comparing the medium-term efficacy of RTX used as maintenance therapy in AQP4positive NMOSD and myelin oligodendrocyte glycoprotein (MOG)-associated disorders. ${ }^{8}$ The objectives were twofold: to determine first the incidence and prognostic factor(s) of hypogammaglobulinemia in patients with CNS inflammatory diseases treated with RTX as a maintenance regimen and second the incidence and prognostic factor(s) of infections during this therapy.

\section{Methods}

\section{Study Population and RTX Administration Scheme}

From 2012, we prospectively included in an observational study all consecutive adults with MOG or AQP4 antibody disorders receiving RTX at the tertiary neuroinflammatory center of Marseille by using a standardized protocol (see Durozard et al. ${ }^{8}$ for more details). Briefly, inclusion criteria were age $>18$ years, at least 1 demyelinating event of the CNS during the previous 18 months, positive for serum MOG or AQP4 antibody, and initiating RTX by an individualized dosing schedule adapted to memory B-cell measurement. The induction treatment consisted of 1,000 $\mathrm{mg}$ infused twice at a 2-week intervals or $375 \mathrm{mg} / \mathrm{m}^{2}$ per week for 4 weeks. The maintenance regimen consisted of a single infusion of $1,000 \mathrm{mg}$. Infusions of RTX were guided by an individualized dosing schedule according to the frequency of reemerging memory B cells (CD27-positive B cells). ${ }^{8}$

\section{Standard Protocol Approvals, Registrations, and Patient Consents}

Each participant gave free and informed written consent for anonymized use of clinical, MRI and biological data for research purposes (NOMADMUS cohort). For the present study, only data for patients included before December 2018 are reported, and only data acquired before spring 2020 were analyzed. In case of immunoglobulin replacement, we stopped the analysis of the data at the date of initiation.

\section{Medical Visits}

Physical examination was performed at each RTX infusion, 3 months after each infusion, at each relapse, and in case of adverse events. At inclusion in the present prospective study, we gave all participants the phone number of our indoor neuroinflammatory unit, which is open $24 \mathrm{~h} / \mathrm{d}$ and $7 \mathrm{~d} / \mathrm{wk}$. We informed each patient about the need to call the center in case of fever or new physical signs. At each visit to our center, at least every 3 months, the examination was performed by the same experienced neurologists (A.R., C.B., A.M., or B.A.) of the university hospital of Marseille (France). A prespecified protocol with directed questions was applied concerning the most frequent potential adverse event associated with RTX treatment, namely infection. Full clinical examination including temperature measurement was performed at each visit. All infections were noted and graded according to the Common Terminology Criteria for Adverse Events v4.0: grade 1: asymptomatic, pathologic, or radiographic findings only; grade 2: localized, local, or noninvasive intervention indicated; grade 3: IV antibiotic, antifungal, or antiviral intervention indicated, interventional radiology or operative intervention indicated; grade 4 : life-threatening consequences (e.g., septic shock, hypotension, acidosis, and necrosis); and grade 5: death. Symptomatic infection (grade $\geq 2$ ) was retained with only the following criteria: physical signs suggestive of infection associated with at least fever or positive radiographic or positive laboratory findings.

\section{Immunoglobulin Measurement}

The immunoglobulin level was measured at a single diagnostic laboratory (University Hospital of Marseille) before RTX onset and before each RTX infusion. We defined 4 categories of IgG level: normal level, $\geq 7 \mathrm{~g} / \mathrm{L}$; hypo-IgG level 
1, 6-7 g/L; hypo-IgG level 2, 4-6 g/L; hypo-IgG level 3, 2-4 $\mathrm{g} / \mathrm{L}$, and hypo-IgG level $4, \leq 2 \mathrm{~g} / \mathrm{L}$. We graded the serum IgG level after RTX onset on the basis of the nadir serum IgG concentration during follow-up. We also assessed the proportion of patients showing sustained decrease (maintenance at the same level), partial reversibility (increase to a higher level), or complete normalization. IgA and IgM levels were also measured (normal levels $\geq 0.7$ and $0.4 \mathrm{~g} / \mathrm{L}$, respectively). We also assessed the proportion of patients showing sustained decrease (maintenance under the normal level) or complete normalization of levels.

\section{Statistical Analysis}

The proportions of patients with hypogammaglobulinemia before and after RTX onset were compared by the Fisher exact test. The risk of symptomatic infections was assessed with multivariate Cox proportional hazard models for recurrent events. Variables tested were disease duration and age at RTX onset, sex, existence of urinary tract dysfunction defined as the presence of urinary urgency and/or voiding difficulties, swallowing dysfunction, immunoglobulin levels, and dosing intervals. Patient ID was included as a cluster variable to account for intraindividual correlation of observations. A similar multivariate model was used to investigate the occurrence of reduced IgG level during RTX treatment. Here, we computed hazard ratios (HRs) and 95\% CIs for the following variables at the onset of the RTX treatment: age, sex, disease duration, Expanded Disability Status Scale score, previous immunosuppressive therapy before RTX, RTX induction regime, and dosing intervals. $p<0.05$ was considered statistically significant. All analyses were performed with Statistics in R v4.0.2, including the survival package.

\section{Data Availability}

All data analyzed during this study will be shared anonymized by reasonable request of a qualified investigator to the corresponding author.

\section{Results}

\section{Study Population}

We included 31 (65\%) patients with AQP4 antibodies and 17 (35\%) with MOG antibodies. Results related to the clinical response to RTX in both diseases were previously published ${ }^{8}$ and are not reported here (table 1).

RTX was the first-line therapy for 34 of 48 (71\%) patients. In other patients, previous treatment included mycophenolate mofetil $(\mathrm{n}=6)$, azathioprine $(\mathrm{n}=3)$, methotrexate $(\mathrm{n}=2)$, cyclophosphamide $(n=2)$, interferon beta $(n=2)$, and teriflunomide, natalizumab, glatiramer acetate, dimethyl fumarate, and fingolimod ( $\mathrm{n}=1$ each). The median follow-up after RTX initiation was 3.6 years (range $0.9-8.1$ years). The median number of RTX infusions was 8 (range 2-14). The median and mean duration between 2 RTX infusions was 6 and 5.89 months, respectively (range 1.7-13.7 months). RTX was used as monotherapy in most patients. Steroids were associated with RTX in only 7 of 48 patients and were stopped in 5 of them after several months.

\section{Incidence, Grade, and Type of Infections After RTX Onset}

After RTX onset, we observed 67 symptomatic infections (grade $\geq 2$ ) in 26 of 48 (54\%) patients, including 13 severe infections (grade $\geq 3$ ) in 9 (19\%). The median number of symptomatic infections was 1 (range $0-10)$ per patient. The first symptomatic infection occurred at a median of 15 months (range 0-86 months) after RTX onset. The mean annual rate of symptomatic infections after RTX in the whole group was $0.28(\mathrm{SD}=0.39)$. Urinary tract infections $(\mathrm{n}=28)$ were the most frequent and represented $42 \%$ of all symptomatic infections. Lower respiratory tract infections $(n=14)$ represented the second most frequent infection type (21\%). All patients presented fever and lower respiratory tract signs. Chest X-ray or CT scan was performed in 8 of 14 episodes and confirmed lower respiratory tract infection in all. Nine skin infections were diagnosed clinically and included erysipelas ( $\mathrm{n}$ = 2); 1 each of impetigo, folliculitis, genital herpes simplex, and herpes zoster; and mycosis $(n=2)$. One case of cellulitis was diagnosed clinically and microbiologically. Upper respiratory tract infections $(n=9)$ included otitis media $(n=2)$ diagnosed clinically; sinusitis $(n=3)$ diagnosed clinically and radiographically; sinusitis $(\mathrm{n}=1)$ diagnosed clinically, radiographically and microbiologically; dental abscess $(n=2)$ diagnosed clinically and radiographically; and pharyngitis $(\mathrm{n}=$ 1) diagnosed clinically and microbiologically. Gastrointestinal infections included abscess of the ileum $(n=1)$ diagnosed clinically and by CT scan and candida esophagitis $(n=1)$ diagnosed clinically and microbiologically. One case each of genital infection, enterovirus meningitis, enterovirus meningoencephalitis, and parvovirus B19 infection were diagnosed clinically and microbiologically (table 2 ).

\section{Serious Adverse Events}

In total, 15 serious adverse events occurred and included 13 serious infectious events, 1 case of agranulocytosis and 1 of Crohn disease.

\section{Incidence of Hypogammaglobulinemia}

Reduced IgG level $<7 \mathrm{~g} / \mathrm{L}$ (level $\geq 1$ ) was present in 3 of 48 (6\%) patients (4.71, 6.39, and $5.81 \mathrm{~g} / \mathrm{L}$, respectively) before RTX and occurred in 28 of 48 (58\%) during RTX after a mean of 17 months (range 0-64) $(p<0.0001)$. During RTX, reduced IgG level $<7 \mathrm{~g} / \mathrm{L}$ was sustained in 15 of 48 (31\%) patients, partially recovered in 7 of $48(15 \%)$ and completely recovered in 6 of 48 (13\%). Reduced IgG level $<6 \mathrm{~g} / \mathrm{L}$ (level $\geq 2$ ) was observed in 20 of 48 (42\%) patients after a mean of 14 months (0-64), was sustained in 11 of 48 (23\%), partially recovered in 7 of $48(15 \%)$, and completely recovered in 2 of 48 (4\%). Reduced IgG level $<4 \mathrm{~g} / \mathrm{L}$ (level $\geq 3$ ) was observed in 5 of $48(10 \%)$ patients after a mean of 1.6 months $(0-5)$, was sustained in 3 of $48(6 \%)$, partially recovered in 2 of $48(4 \%)$, and completely recovered in none (0\%). Reduced IgG level 
Table 1 Patient Characteristics $(n=48)$

\begin{tabular}{|c|c|}
\hline Characteristics & Value \\
\hline Age, $y$, mean (SD) & $46.6(14)$ \\
\hline Sex ratio (F/M) & $3.4(37 / 11)$ \\
\hline \multicolumn{2}{|l|}{ Disease type, no. (\%) of patients } \\
\hline AQP4-positive NMOSD & $31(65)$ \\
\hline MOG-associated disorder & $17(35)$ \\
\hline Disease duration, $y$, median (range) & $6.2(1.8-35.1)$ \\
\hline EDSS score, median (range) & $2(0-6.5)$ \\
\hline Urinary tract dysfunction, no. (\%) of patients & $21(44)$ \\
\hline Swallowing dysfunction, no. (\%) of patients & $0(0)$ \\
\hline RTX as first-line therapy, no. (\%) of patients & $34(71)$ \\
\hline \multicolumn{2}{|l|}{ Previous treatment, no. (\%) of patients } \\
\hline Mycophenolate mofetil & $6(13)$ \\
\hline Azathioprine & $3(6)$ \\
\hline Methotrexate & $2(4)$ \\
\hline Cyclophosphamide & $2(4)$ \\
\hline Interferon beta & $2(4)$ \\
\hline Teriflunomide & $1(2)$ \\
\hline Natalizumab & $1(2)$ \\
\hline Glatiramer acetate & $1(2)$ \\
\hline Dimethyl fumarate & $1(2)$ \\
\hline Fingolimod & $1(2)$ \\
\hline No. of RTX infusions, median (range) & $8(2-14)$ \\
\hline Duration between 2 RTX infusions, mo, median (range) & $6(1.7-13.7)$ \\
\hline Follow-up after RTX initiation, y, median (range) & $3.6(0.9-8.1)$ \\
\hline
\end{tabular}

Abbreviations: AQP4 = aquaporin 4; EDSS = Expanded Disability Status Scale; MOG = myelin oligodendrocyte glycoprotein; NMOSD = neuromyelitis optica spectrum disorder; RTX = rituximab.

$<2 \mathrm{~g} / \mathrm{L}$ (level 4) was not observed in any patients. Reduced IgM level $(<0.4 \mathrm{~g} / \mathrm{L})$ was present in 1 of $48(2 \%)$ patients $(0.26 \mathrm{~g} / \mathrm{L})$ before RTX and 22 of $48(46 \%)$ after RTX after a mean of 13 months (range 0-54) $(p<0.0001)$. After RTX, reduced IgM level $(<0.4 \mathrm{~g} / \mathrm{L})$ recovered in 1 of $48(2 \%)$ patients. Reduced IgA level $(<0.7 \mathrm{~g} / \mathrm{L})$ was present in 3 of 48 (6\%) patients $(0.57,0.28$, and $0.46 \mathrm{~g} / \mathrm{L}$, respectively) before RTX and persisted in the same 3 patients after RTX (0.30, 0.12 , and $0.34 \mathrm{~g} / \mathrm{L}$, respectively) (table 3 ).

Immunoglobulin replacement was started in 5 of 48 patients after a mean of 55 months (range: 24-95 months). In 3 patients, immunoglobulins replacement was started owing to severe hypogammaglobulinemia associated with 1 episode of infection. In the 2 remaining patients, hypogammaglobulinemia was not associated with infection but occurred in patients with MOG antibody-associated disorder. In these patients, we decided to initiate IV immunoglobulins for replacement but also as maintenance therapy according to the recent published results related to the limited clinical response to RTX of MOG-associated disease ${ }^{8,9}$ and publications suggesting the efficacy of IV immunoglobulin in MOG antibody-associated disorder. ${ }^{10}$

\section{Predictors of Symptomatic Infections After RTX}

The main variables explaining the risk of symptomatic infections after RTX were the presence of urinary tract dysfunction $(\mathrm{HR}=34,95 \% \mathrm{CI} 4-262, p<0.001)$, the dosing intervals $(\mathrm{HR}=0.98,95 \% \mathrm{CI} 0.97-0.99, p<0.001)$, and the interaction between the IgG level and the presence of urinary tract dysfunction ( $\mathrm{HR}=0.67,95 \%$ CI $0.53-0.85, p<0.005)$. We did not use a cutoff for the IgG level in the model. IgG was 
Table 2 Symptomatic Infections (Grade $\geq 2$ ) After Rituximab

\begin{tabular}{|c|c|}
\hline Type of infection & No. of episodes (\%) \\
\hline Urinary tract infections & $28(42)$ \\
\hline Lower respiratory tract infections & $14(21)$ \\
\hline Skin infections & $10(15)$ \\
\hline Upper respiratory tract infections & $9(13)$ \\
\hline Gastrointestinal infection & $2(3)$ \\
\hline Enterovirus meningitis & $1(1.5)$ \\
\hline Enterovirus encephalitis & $1(1.5)$ \\
\hline Genital infection & $1(1.5)$ \\
\hline Parvovirus B19 & $1(1.5)$ \\
\hline Total & 67 \\
\hline
\end{tabular}

included as a continuous variable. Applying a commonly used cutoff of $6 \mathrm{~g} / \mathrm{L}$ to define hypogammaglobulinemia gives similar results. For patients with reduced IgG level $<6 \mathrm{~g} / \mathrm{L}$ after RTX $(n=20)$, the mean annual rate of symptomatic infections was $0.33(\mathrm{SD}=0.52)$ before the emergence of reduced $\operatorname{IgG}$ level $<6 \mathrm{~g} / \mathrm{L}$ and was $1.1(\mathrm{SD}=1.96)$ after.

\section{Predictors of Hypogammaglobulinemia After RTX}

We limited the analysis to potential predictors of reduced IgG level because only the IgG level interacted with the infection risk during RTX. The main variables explaining the risk of reduced IgG level $<6 \mathrm{~g} / \mathrm{L}$ after RTX onset were male sex $(\mathrm{HR}=4,95 \%$ CI 1.4-11.4, $p<0.01)$, previous immunosuppressive therapy before RTX $(\mathrm{HR}=3.4,95 \%$ CI 1.2-10, $p<0.05)$, and a trend for the dosing intervals $(\mathrm{HR}=0.99,95 \%$ CI $0.98-1, p=0.06)$.

\section{Discussion}

In the present prospective study, patients with CNS inflammatory diseases treated with RTX used as maintenance therapy frequently showed reduced IgG level, which increased the risk of symptomatic infections of the most vulnerable patients. Male sex and the use of previous immunosuppressive therapy before RTX were the best predictors of reduced IgG level during RTX treatment.

Hypogammaglobulinemia after B cell-depleting therapy is now well recognized in patients with hematologic and autoimmune rheumatic diseases. ${ }^{11}$ For patients with lymphoma, confounding factors such as chemotherapy, bone marrow transplantation, and lymphoma itself probably contribute to hypogammaglobulinemia after RTX. In contrast, in rheumatic and multisystem autoimmune diseases, RTX can be the main factor underlying hypogammaglobulinemia. In these diseases, the incidence of hypogammaglobulinemia is highly variable, ranging from $10 \%$ to $50 \%$ depending on the number of cycles and the disease. In fact, most studies have been retrospective, included patients with various RTX regimens and frequently associated other immunosuppressive drugs, which limits comparison.

In the present study, including mostly patients naive of immunosuppressive agents, the proportion of patients with persistent reduced IgG level $<7,6$, and $4 \mathrm{~g} / \mathrm{L}$ after RTX was $31 \%, 23 \%$, and $6 \%$, respectively. Few studies have provided data on the incidence of hypogammaglobulinemia during maintenance therapy with anti-CD20 agents for neuroinflammatory diseases. Pivotal randomized controlled trials of RTX and ocrelizumab have reported a low incidence of hypogammaglobulinemia during relatively short observational periods. ${ }^{12-14}$ In the pivotal phase 2 study testing RTX in relapsing-remitting MS, $7.8 \%$ of patients showed hypogammaglobulinemia ${ }^{12}: 2$ infusions of RTX were administered at a 2-week interval and patients were followed for 12 months. In the phase 3 study testing ocrelizumab vs interferon beta-1a in relapsing-remitting MS, the incidence of hypogammaglobulinemia and reduced IgG level was $16.5 \%$ and $1.5 \%$ at 2 years after 4 doses at a 6 -month interval. ${ }^{13}$ In the phase 3 study testing ocrelizumab vs placebo in primary progressive MS, the incidence was $15.5 \%$ and $1.1 \%$, respectively, at 2.5 years after 5 doses at a 6-month interval. ${ }^{14}$ Recently, data were published from the 5-year open-label extension of the phase 3 study testing ocrelizumab vs interferon beta-1a in relapsingremitting $\mathrm{MS}^{15}$ : at 5 years, for $5.4 \%$ of the patients who completed the study (88.5\%), the reduced IgG level was $<5.68 \mathrm{~g} / \mathrm{L}$. Unfortunately, the study did not compare the incidence of reduced IgG level between patients who received ocrelizumab since the study onset ( 5 years) and after interferon beta-1a treatment ( 3 years). Moreover, a potential high incidence of reduced IgG level for patients who did not complete the study cannot be excluded. Nevertheless, potential generalization from randomized controlled trials is problematic because these studies subselected patients who tolerated the therapy, 
Table 3 Reduced IgG Level After RTX Initiation

\begin{tabular}{lllll}
\hline $\begin{array}{l}\text { IgG } \\
\text { level, g/L }\end{array}$ & $\begin{array}{l}\text { Total (reduced lgG level at any time after RTX), } \\
\text { no. (\%) of patients }\end{array}$ & $\begin{array}{l}\text { Sustained, no. (\%) of } \\
\text { patients }\end{array}$ & $\begin{array}{l}\text { Partially recovered, no. (\%) } \\
\text { of patients }\end{array}$ & $\begin{array}{l}\text { Completely recovered, no. } \\
\text { (\%) of patients }\end{array}$ \\
\hline$<7$ & $28 / 48(58)$ & $15 / 48(31)$ & NA & $13 / 48(27)$ \\
\hline$<6$ & $20 / 48(42)$ & $11 / 48(23)$ & $7 / 48(15)$ & $2 / 48(4)$ \\
\hline$<4$ & $5 / 48(10)$ & $3 / 48(6)$ & $2 / 48(4)$ & $0 / 48(0)$ \\
\hline$<2$ & $0 / 48(0)$ & $0 / 48(0)$ & $0 / 48(0)$ & $0 / 48(0)$ \\
\hline
\end{tabular}

Abbreviations: IgG = immunoglobulin G; NA = not applicable; RTX = rituximab.

whereas those with comorbidities or with previous treatment with immunosuppressive drugs were often excluded from trials. Therefore real-world data from cohort studies are necessary. Two real-word retrospective observational studies in patients with NMO receiving RTX demonstrated increased incidence of hypogammaglobulinemia close to the incidence we report. ${ }^{16,17}$ For a group of 15 patients with NMOSD receiving a mean of 6 RTX infusions during a median of 70 months, ${ }^{16} 73 \%$ showed reduced IgG level $<7 \mathrm{~g} / \mathrm{L}$ and $20 \%$ severe reduced IgG level, $<4$ $\mathrm{g} / \mathrm{L}$. Among 50 patients with NMOSD receiving RTX for several years, the proportion with hypogammaglobulinemia and reduced IgG level was $64 \%$ and $38 \%$, respectively. ${ }^{17}$ Probably that the relative long treatment period and the inclusion of patients with other immunosuppressive agents before RTX affect the incidence of reduced IgG level after RTX as evidenced here. Maintenance therapy with RTX during the long term may have a higher impact on humoral immunity because long-lived plasma cells that are not depleted by anti-CD20 therapies may depend on regular replenishment by the B-cell progenitor pool that is regularly depleted by maintenance therapy.

The second important result of the study relates to the high frequency of symptomatic and severe infections observed in $54 \%$ and $19 \%$ of patients, respectively. This high frequency is probably multifactorial. First, contrary to autoimmune rheumatic diseases, urinary tract or swallowing dysfunctions are common in patients with CNS inflammatory diseases and represent a major risk factor for infections. In the present study, urinary tract dysfunctions were present in $44 \%$ of patients, but no patient exhibited swallowing dysfunction. This finding explains why the presence of urinary tract dysfunction in patients was the main modulator of the infection risk in the present sample. Second, the reduced IgG level increased the risk of infection associated with the presence of urinary tract dysfunction. This interaction suggests that one of the most vulnerability factors of infection in neurologic patients represented by urinary tract dysfunction is modulated by RTX-induced hypogammaglobulinemia. The effect of RTX-induced hypogammaglobulinemia on the rate of infection was reported recently in 2 retrospective studies including large cohorts of patients with autoimmune rheumatic diseases ${ }^{2}$ and CNS inflammatory diseases. ${ }^{18}$ Similarly, these studies revealed an association between the reduced IgG level and the rate of infection. In patients with CNS inflammatory diseases, Vollmer et al. ${ }^{18}$ found several other factors associated with risk of infection, including duration of RTX therapy, male sex, increased disability, prior exposure to immunosuppression, and lymphopenia. In the present study, prior exposure to immunosuppression and male sex were associated with only reduced IgG level during RTX treatment but not infection risk. These discrepancies are probably due to the limited sample size and the high homogeneity of the clinical characteristics of patients in our study. Particularly, most patients were included at the onset of the disease, received RTX as first-line therapy, and exhibited limited disability.

Finally, we evidenced that dosing intervals of RTX interacted with the risk of symptomatic infections and the risk of reduced IgG level. Patients with shorter dosing intervals due to earlier reemergence of memory B cells had a higher risk of symptomatic infection probably due to a higher risk of reduced IgG level. This suggests that extending dosing of anti-CD20 agents could improve their safety. In AQP4positive NMOSD, intensive maintenance regimen with anti-CD20 agents seems necessary because relapses can occur when memory B cells are slightly repopulated, ${ }^{8,19-21}$ but in MS, extending dosing of RTX is associated with a low risk of relapse or MRI activity, as suggested by recent studies. ${ }^{22,23}$ Future prospective studies performed in large sample are required to confirm that extending dosing of anti-CD20 agents could improve safety in MS without significant loss of efficacy.

This prospective study confirms the safety signal reported recently in a large retrospective study relative to the infectious risk associated with anti-CD20 agents used as maintenance therapy in CNS inflammatory diseases. ${ }^{1}$ Importantly, the present study showed that reduced level of IgG induced by anti-CD20 agents contributes to the emergence of infections and that the risk of infections is associated with dosing intervals.

\section{Study Funding}

No targeted funding reported.

\section{Disclosure}

All authors certify that there is no financial interest related to this study. Go to Neurology.org/NN for full disclosures. 


\section{Publication History}

Received by Neurology: Neuroimmunology \& Neuroinflammation September 25, 2020. Accepted in final form February 5, 2021.

Appendix Authors

\begin{tabular}{lll}
\hline Name & Location & Contribution \\
\hline $\begin{array}{lll}\text { Alexandre } \\
\text { Avouac, MD }\end{array}$ & $\begin{array}{l}\text { La Timone Hospital, } \\
\text { Aix-Marseille } \\
\text { University, France }\end{array}$ & $\begin{array}{l}\text { Major role in the acquisition } \\
\text { of data }\end{array}$ \\
\hline
\end{tabular}

Adil Maarouf, La Timone Hospital, MD, PhD University, France

Drafting/revision of the manuscript for content, including medical writing for content, and analysis or interpretation of data

\begin{tabular}{|c|c|c|}
\hline $\begin{array}{l}\text { Jan-Patrick } \\
\text { Stellmann, } \\
\text { MD, PhD }\end{array}$ & $\begin{array}{l}\text { La Timone Hospital, } \\
\text { Aix-Marseille } \\
\text { University, France }\end{array}$ & $\begin{array}{l}\text { Analysis or interpretation of } \\
\text { data }\end{array}$ \\
\hline $\begin{array}{l}\text { Audrey Rico, } \\
\text { MD, PhD }\end{array}$ & $\begin{array}{l}\text { La Timone Hospital, } \\
\text { Aix-Marseille } \\
\text { University, France }\end{array}$ & Study concept or design \\
\hline $\begin{array}{l}\text { Clemence } \\
\text { Boutiere, MD }\end{array}$ & $\begin{array}{l}\text { La Timone Hospital, } \\
\text { Aix-Marseille } \\
\text { University, France }\end{array}$ & Study concept or design \\
\hline $\begin{array}{l}\text { Sarah } \\
\text { Demortiere, } \\
\text { MD }\end{array}$ & $\begin{array}{l}\text { La Timone Hospital, } \\
\text { Aix-Marseille } \\
\text { University, France }\end{array}$ & Study concept or design \\
\hline $\begin{array}{l}\text { Romain } \\
\text { Marignier, } \\
\text { MD, PhD }\end{array}$ & $\begin{array}{l}\text { Pierre Wertheimer } \\
\text { Hospital, Lyon, France }\end{array}$ & Study concept or design \\
\hline $\begin{array}{l}\text { Jean Pelletier, } \\
\text { MD, PhD }\end{array}$ & $\begin{array}{l}\text { La Timone Hospital, } \\
\text { Aix-Marseille } \\
\text { University, France }\end{array}$ & Study concept or design \\
\hline $\begin{array}{l}\text { Bertrand } \\
\text { Audoin, MD, } \\
\text { PhD }\end{array}$ & $\begin{array}{l}\text { La Timone Hospital, } \\
\text { Aix-Marseille } \\
\text { University, France }\end{array}$ & $\begin{array}{l}\text { Drafting/revision of the } \\
\text { manuscript for content, } \\
\text { including medical writing for } \\
\text { content; study concept or } \\
\text { design; and analysis or } \\
\text { interpretation of data }\end{array}$ \\
\hline
\end{tabular}

\section{References}

1. Luna G, Alping P, Burman J, et al. Infection risks among patients with multiple sclerosis treated with fingolimod, natalizumab, rituximab, and injectable therapies. JAMA Neurol 2020;77:184-191.
2. Md Yusof MY, Vital EM, McElvenny DM, et al. Predicting severe infection and effects of hypogammaglobulinemia during therapy with rituximab in rheumatic and musculoskeletal diseases. Arthritis Rheumatol 2019;71:1812-1823.

3. Gottenberg JE, Ravaud P, Bardin T, et al. Risk factors for severe infections in patients with rheumatoid arthritis treated with rituximab in the autoimmunity and rituximab registry. Arthritis Rheumatol 2010;62:2625-2632.

4. Barmettler S, Ong MS, Farmer JR, Choi H, Walter J. Association of immunoglobulin levels, infectious risk, and mortality with rituximab and hypogammaglobulinemia. JAMA Netw Open 2018;1:e184169.

5. Boleto G, Avouac J, Wipff J, et al. Predictors of hypogammaglobulinemia during rituximab maintenance therapy in rheumatoid arthritis: a 12-year longitudinal multicenter study. Semin Arthritis Rheum 2018;48:149-154.

6. Casulo C, Maragulia J, Zelenetz AD. Incidence of hypogammaglobulinemia in patients receiving rituximab and the use of intravenous immunoglobulin for recurrent infections. Clin Lymphoma Myeloma Leuk 2013;13:106-111.

7. Wijetilleka S, Jayne D, Mukhtyar C, Karim MY. Iatrogenic antibody deficiency from B-cell targeted therapies in autoimmune rheumatic diseases. Lupus Sci Med 2019;6: e000337.

8. Durozard P, Rico A, Boutiere C, et al. Comparison of the response to rituximab between myelin oligodendrocyte glycoprotein and aquaporin-4 antibody diseases. Ann Neurol 2020;87:256-266.

9. Whittam DH, Cobo-Calvo A, Lopez-Chiriboga AS, et al. Treatment of MOG-IgGassociated disorder with rituximab: an international study of 121 patients. Mult Scler Relat Disord 2020;44:102251.

10. Chen JJ, Flanagan EP, Bhatti MT, et al. Steroid-sparing maintenance immunotherapy for MOG-IgG associated disorder. Neurology 2020;95:e111-e120.

11. Sacco KA, Abraham RS. Consequences of B-cell-depleting therapy: hypogammaglobulinemia and impaired B-cell reconstitution. Immunotherapy 2018;10: 713-728.

12. Hauser SL, Arnold DL, Fox RJ, Sarkar N, Smith CH. B-cell depletion with rituximab in relapsing-remitting multiple sclerosis. N Engl J Med 2008;358:676-688.

13. Hauser SL, Bar-Or A, Comi G, et al. Ocrelizumab versus interferon beta-1a in relapsing multiple sclerosis. N Engl J Med 2017;376:221-234.

14. Montalban X, Hauser SL, Kappos L, et al. Ocrelizumab versus placebo in primary progressive multiple sclerosis. N Engl J Med 2017;376:209-220.

15. Hauser SL, Kappos L, Arnold DL, et al. Five-years of ocrelizumab in relapsing multiple sclerosis: OPERA studies open-label extension. Neurology 2020;95:e1854-e1867.

16. Marcinnò A, Marnetto F, Valentino $\mathrm{P}$, et al. Rituximab-induced hypogammaglobulinemia in patients with neuromyelitis optica spectrum disorders. Neurol Neuroimmunol Neuroinflamm 2018;5:e498.

17. Tallantyre EC, Whittam DH, Jolles S, et al. Secondary antibody deficiency: a complication of anti-CD20 therapy for neuroinflammation. J Neurol 2018;265: $1115-1122$.

18. Vollmer BL, Wallach AI, Corboy JR, Dubovskaya K, Alvarez E, Kister I. Serious safety events in rituximab-treated multiple sclerosis and related disorders. Ann Clin Transl Neurol 2020;7:1477-1487.

19. Kim SH, Kim W, Li XF, Jung IJ, Kim HJ. Repeated treatment with rituximab based on the assessment of peripheral circulating memory B cells in patients with relapsing neuromyelitis optica over 2 years. Arch Neurol 2011;68:1412-1420.

20. Kim SH, Huh SY, Lee SJ, Joung A, Kim HJ. A 5-year follow-up of rituximab treatment in patients with neuromyelitis optica spectrum disorder. JAMA Neurol 2013;70: 1110-1117.

21. Kim SH, Jeong IH, Hyun JW, et al. Treatment outcomes with rituximab in 100 patients with neuromyelitis optica: influence of FCGR3A polymorphisms on the therapeutic response to rituximab. JAMA Neurol 2015;72:989-995.

22. Maarouf A, Rico A, Boutiere C, et al. Extending rituximab dosing intervals in patients with MS during the COVID-19 pandemic and beyond? Neurol Neuroimmunol Neuroinflamm 2020;7:e825.

23. Baker D, Pryce G, James LK, Marta M, Schmierer K. The ocrelizumab phase II extension trial suggests the potential to improve the risk: benefit balance in multiple sclerosis. Mult Scler Relat Disord 2020;44:102279. 


\section{Neurology \\ Neuroimmunology \& Neuroinflammation}

\section{Rituximab-Induced Hypogammaglobulinemia and Infections in AQP4 and MOG Antibody-Associated Diseases \\ Alexandre Avouac, Adil Maarouf, Jan-Patrick Stellmann, et al. \\ Neurol Neuroimmunol Neuroinflamm 2021;8; \\ DOI 10.1212/NXI.0000000000000977}

This information is current as of March 15, 2021

\section{Updated Information \& Services}

References

Citations

Subspecialty Collections

Permissions \& Licensing

Reprints including high resolution figures, can be found at: http://nn.neurology.org/content/8/3/e977.full.html

This article cites 23 articles, 3 of which you can access for free at: http://nn.neurology.org/content/8/3/e977.full.html\#\#ref-list-1

This article has been cited by 5 HighWire-hosted articles: http://nn.neurology.org/content/8/3/e977.full.html\#\#otherarticles

This article, along with others on similar topics, appears in the following collection(s):

All Infections

http://nn.neurology.org//cgi/collection/all_infections

Devic's syndrome

http://nn.neurology.org//cgi/collection/devics_syndrome

Information about reproducing this article in parts (figures,tables) or in its entirety can be found online at:

http://nn.neurology.org/misc/about.xhtml\#permissions

Information about ordering reprints can be found online: http://nn.neurology.org/misc/addir.xhtml\#reprintsus

Neurol Neuroimmunol Neuroinflamm is an official journal of the American Academy of Neurology.

Published since April 2014, it is an open-access, online-only, continuous publication journal. Copyright

Copyright (C) 2021 The Author(s). Published by Wolters Kluwer Health, Inc. on behalf of the American

Academy of Neurology.. All rights reserved. Online ISSN: 2332-7812.

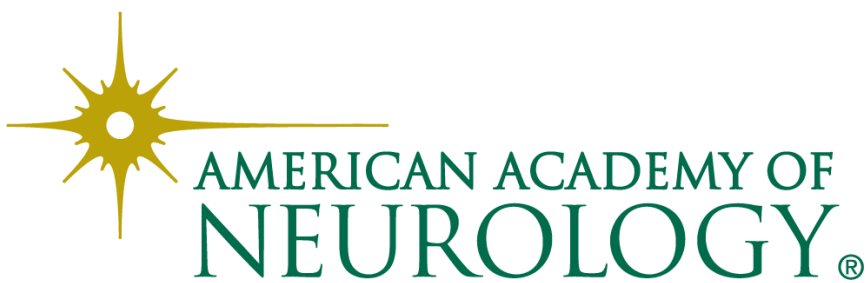

